\title{
Developing and testing an m-Learning tool to facilitate guided-informal learning in agriculture
}

\author{
Uvasara Dissanayeke $^{* \# 1}$, K.P.Hewagamage ${ }^{\# 2}$, Robert Ramberg ${ }^{\$ 3}$ and Gihan Wikramanayake ${ }^{\# 4}$ \\ *Department of Agricultural Extension, University of Peradeniya, Peradeniya, Sri Lanka \\ 1uvasarad@pdn.ac.1k \\ ${ }^{\#}$ University of Colombo School of Computing, University of Colombo, Sri Lanka \\ ${ }^{2} \mathrm{kph@ucsc.cmb.ac.1k}$ \\ ${ }^{\$}$ Department of Computer and Systems Sciences, Stockholm University, Sweden \\ 3robban@dsv.su.se \\ 4gnw@ucsc.cmb.ac.1k
}

\begin{abstract}
Constructivism learning theory emphasizes the importance of collaborations in creating a shared understanding. In the given study, collaborations facilitated on a mobile SMS based Twitter platform as an effort to design mobile-based guided-informal learning. The objectives of the study were i) designing m-learning contents for Twitter, ii) facilitating collaborative m-Learning, and iii) testing effectiveness of mLearning tool. A mobile learning approach (mLA) was designed in collaboration with users, following design-based research theories. Data were collected using participatory methods, questionnaires, and logged data in the mLA. Descriptive methods, network analysis methods and mean comparisons used in the data analysis. Members of a young farmer club in Kandy, Sri Lanka participated in the research process for two years.

Pedagogical tools, such as lessons, interactions, assessments and feedback, designed to match with Twitter functionalities and features. Participation in the mLA has improved knowledge in learners, and has created collaborative learning opportunities. Learners were generally satisfied with mLA as a guided-informal learning tool. The drawbacks were mainly due to technical problems, and limitations in the SMS based platform, which has limited opportunities to acquire higher order learning skills. Future implementations of the mLA model need to focus on designing mobile based applications for Smartphones in creating more collaborative and interactive learning spaces.
\end{abstract}

Keywords - Mobile learning, Twitter, SMS, Collaborative learning, informal learning, farmers, Sri Lanka

\section{INTRODUCTION}

Constructivism theory suggests learning as a social activity, in which learners closely associate with others in the society such as teachers, peers, and experts during the process of learning. Constructivism thus emphasizes the need for effective collaborations in creating shared understanding [1]. This study attempted to facilitate learner collaborations using a mobile SMS based Twitter implementation. Users' communications and interactions in Twitter were studied to understand how to use mobile SMS based Twitter in facilitating collaborative learning.

The user community consisted of an Agriculture Instructor (AI) and a group of farmers. The learning needs of the farmers were previously addressed using a traditional non-formal learning system (TNLS). The users were interested in mobile technology enhanced learning approach (mLA) as a supplement for TNLS as it was found to be challenged due to several factors [2]. The most prominent factors were identified as cost and time involved in travelling, inefficiencies in the systems for interactions and communication, and difficulties in scheduling face-to-face discussion classes. A mobile-based guided-informal learning solution (mLA) was developed to supplement present TNLS as a solution, using a design based research approach [3]. The study was conducted for a period of two years with the young farmer community in Ankumbura, Kandy District, Sri Lanka.

Main research questions addressed in the study were (i) what are the user requirements and specifications, (ii) how to network user community to facilitate effective collaborations, (iii) how to design learning contents leading to guided-informal learning, (iv) is mLA an effective learning tool, and (v) what are the problems and limitations in the mLA model. The paper begins with a literature review to define the important concepts addressed, followed with methodology, findings, discussion and conclusions.

\section{LITERATURE}

\section{A) Learning theories}

1) Constructivism: Constructivism theory suggests learners construct their own understanding and knowledge on the world through experiencing things and reflecting on those experiences. Learning occurs when learners try to assign meanings for their experiences based on their previous experiences and pervious knowledge. According to the constructivism theory, learning is regarded as a social activity, as a learner closely associates with others in the society [1]. We have built upon a constructivist perspective in the design and development of the mLA as well as in explaining the processes of learning taking place in the mLA.

Constructivism, as a learning theory, is characterized by several features such as encouragement of multiple perspectives of concepts and contents, teachers role as a facilitator, students playing a central role in mediating and controlling learning, knowledge construction through collaboration, developing higher-order thinking skills, and deep understanding through problem solving [4]. 
2) Collaborative learning: Collaborative learning happens when two or more people learn or attempt to learn something together. Collaborations take place in face-to-face situations as well as technology mediated learning situations. Computer-supported collaborative environments provide opportunities for learners to interact with others using computer based technologies [5]. For instance, wireless handhelds can support a group of learners to collaborate with each other, facilitating knowledge creation [6]. Social networking tools also support learner collaborations, when designing technology mediated learning environments [7]. Participation in learner oriented mobile-based social networks has enhanced knowledge sharing attitudes while providing opportunities to expand learning and social space.

Technology enhanced collaborative learning settings have been designed with appropriate mechanisms to facilitate user collaborations. For instance discussion forums, phone discussions, and text messaging can facilitate user collaborations in a learning settings.

Selecting the most appropriate platform to offer collaboration for a given context could be a difficult task. Use, and access to the given technology, and ownership are considered as important determinants when selecting appropriate platforms to facilitate collaborations [8]-[10]. Poor or inadequate access to these resources may result in leaving behind some of the learners, which affect effective collaborations. Thus, in this research, ownership of the devices and technology are considered as pre-requisites in designing effective collaborations [10].

3) Mobile learning, informal learning and non-formal learning: Mobile learning has been mostly defined in relation to e-learning. However, e-Learning can be considered as more compatible with classroom environment, while m-learning calls for environment and time independent pedagogy [11]. A comparison conducted between the two disciplines have described m-Learning as suitable for informal learning, situated learning, and collaborative learning. M-learning can be defined as 'learning across multiple contexts, through social and content interactions, using personal mobile electronic devices'[12]. Thus, pedagogy, mobile devices, learning context and social interactions can be identified as the most important constructs in a m-Learning situation. The context of learning concerned in this paper, tailors mostly guided-informal learning as related to improving knowledge on general agriculture practices and technologies of the farmer community.

'Informal learning is one of the forms of lifelong learning, in which an individual other than the learner, sets learning goals while the learner decides how it is to be learned' [13]. Thus the individual has partial control in the decision making process of when and how to learn. In non-formal learning systems a learner has only a partial control over the method of learning [13]. Non-formal learning is mostly conducted in the form of workshops, training programmes or field demonstrations. The learner initially decides what s/he wishes to learn, however the instructor decided how it is to be taught.

4) Assessment of learning: Assessment of learning is an important practice to determine learner achievement of learning goals. Assessments are usually conducted by gathering information on learner performances. Assessments are classified as summative and formative mainly depending on the timing during the learning process. Summative assessment refers to evaluating performance of a learner at the end of a learning module or course [14]. Formative assessments are conducted throughout the learning sessions as part of the instructional process [15]. Formative assessments are useful to inform teaching practices and to give necessary feedback for learners to improve learning. Summative assessments are important to summarize the learner performances however this would not have an immediate impact on the learning [14].

5) Feedback: Feedback refers to providing information on the actual states of learner performance against a set standard such as learning objectives. Feedback conveys useful information for recipient to improve performances [16]. Providing an informative, positive and immediate feedback can encourage and motivate learners intrinsically [17]. Feedback was given to learners mainly to enhance the learning experience by correcting the mistakes and to emphasizing important facts.

\section{B) SMS based methods in m-Learning}

SMS based m-Learning approaches have been adopted in different settings including universities [18], [19] and distance education [20], [21]. SMS is the most basic and simplest form of facility available in any mobile phone thus, use of SMS based approach is also sustainable in terms of costs, efforts, and resources [21]. Furthermore SMS is considered as one of the effective ways to overcome the barrier of 'device variability' when designing m-learning solutions. It has benefits such as equitable use, flexible use, tolerance for error, low physical and technical effort and encourage of multiple methods of learning [22]. SMS based technologies seem to be more effective and simple when compared to browser based methods because the latter has the risk of connection problems [23].

\section{C) Design based research}

Design-based research is defined as a 'systematic but flexible methodology aimed to improve educational practices through iterative analysis, design, development, and implementation, based on collaboration among researchers and practitioners in real-world settings and leading to contextually-sensitive design principles and theories' [24]. Design-based approach is suitable for research carried out in real world settings [25]. The researchers collaborate with the practitioners to identify and test learning solutions, continuously involving them in the design process. These collaborations often involved complex social interactions and sharing ideas [25]. Such collaborative approaches will be beneficial especially when designing technology enhanced learning environments, leading to construct effective pedagogical models, based on real needs of instructors and learners [26].

Design-based approaches have been widely practiced in mobile learning research [26][27][28][29]. One of the main strengths in design-based research process is the iterative testing procedures. The learning solution is tested with the stakeholders using iterative cycles such that stakeholder ideas are incorporated in the design process. The iterations help researchers to match pedagogical requirements with the 
learning context and user requirements [30]. Basic characteristics of design-based research can be identified as pragmatic, grounded, interactive, iterative, flexible, integrative, and contextual [5].

\section{D) Twitter in mobile learning}

Twitter is one of the most popular micro-blogging services, which allows users to share short messages. Twitter has been used for various purposes including teaching practice to promote active and informal learning [12][13][33], assessment of training [34] and during conferences to enhance the knowledge of a given community through micro connecting to a diverse online audience [35]. Using Twitter in education has increased student engagement and improved performances [36] while mobilizing faculty staff into a more active and participatory role. Use of micro-blogging in class situations have been instrumental in promoting informal learning [32]. It has provided a common platform for students to share information with each other, and contribute for discussions.

Twitter has been able to increase the social presence of online learning by establishing just in time social connections [33]. It has helped in addressing student issues in timely manner, encouraged students to be sensitive to the audience, and facilitated networking with professionals. Informal learning was supported by mainly helping students to discover resources and tools, and by opening up opportunities for lifelong learning. Students were able to establish contacts with faculty staff, which lead them to build-up learning communities, paving way for lifelong learning. Engagement with micro-blogging has also improved students' impressions, participation and enthusiasm during a museum visit [37]. Student interactions in the Twitter platform have helped creating meaningful interactions, resulting collaborative learning.

On the negative side, use of micro-blogging is regarded as a challenging task. When using micro-blogging in educational settings, it is important to motivate students by providing rapid feedback [32]. This helps maintaining student attention however, a teacher would find such a task as demanding and time consuming since they have to engage in discussions 24/7 [38]. Character limitation in Twitter is also considered as a challenge.

\section{METHODOLOGY}

Study community: A group of farmers $(\mathrm{N}=44)$ from a Young Farmer Club in Kandy district participated in the study. The group followed a conventional non-formal system of learning, with their agricultural instructor as the teacher before the initiation of the mobile learning approach. .

\section{A) Research approach}

A design based research approach followed for the study. Accordingly, the development procedure was identified with four consecutive phases namely $i$ ) situation analysis, ii) designing learning solutions, iii) iterative testing and refinement of solution, and $i v$ ) evaluation [39] (Fig. 1). Users participated in all four stages of the research process, making choices and decisions on what they expect from the mobile learning system, following design based research principles [24].

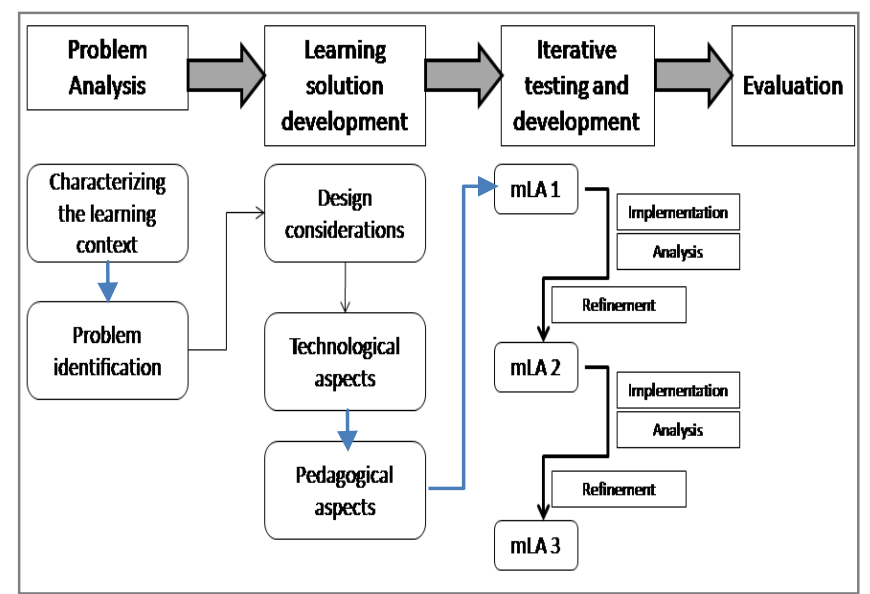

Fig. 1. Design-based research process

1) Problem analysis: During the problem analysis, we characterized the traditional non-formal learning system (TNLS) following Activity theory [2]. Characterizing the learning context was important to see the mobile-based technologies and applications that are presently available with the user community, their familiarity with such technology, affordability of m-learning, and user attitude towards mobile learning [2]. Secondly, we explored the TNLS to see the gaps and problems in the system, that can be improved with a mobile based learning solution. User requirements for a mobile-based learning system were also investigated during this stage.

2) Designing a learning solution: During phase two, a suitable technology that matches with user requirements, was identified. Mobile SMS based Twitter service was identified to host m-learning. Features and functionalities of Twitter, and use of such technologies in building the mlearning were studied using available literature. Pedagogical aspects related to lesson format, feedback, assessments, motivation, interactions and collaborations were designed and developed. Pedagogical aspects were designed in collaboration with the agricultural instructor.

3) Iterative testing and refinement of solution: During phase three, the learning solution developed during phase two were tested with users. Three iterations were conducted (e.g. mLA1, mLA2 and mLA3) and the necessary adjustments were made to the m-learning approach.

4) Evaluation: Learning solution was evaluated using both formative and summative evaluation approaches. Outcomes of the formative assessments were used to provide feedback, and to improve the system. Summative evaluation was conducted to test the effectiveness of $\mathrm{mLA}$ as a learning tool and a collaborative tool.

\section{B) Data collection and analysis}

Design-based research involves working with practitioners. Thus, data collected using participatory methods such as key informant discussions and focus groups. In addition, telephone interviews, SMSs and non-participant observations used to gather information. During the problem analysis and evaluation phases, individual experiences of the study community were studied using questionnaires. Logged 
data in the users' devices as well as in the mLA were also collected. Twitter profile data were collected from Twitter web interface using Tweet download application (http://www.tweetdownload.net).

The data were analyzed using mainly qualitative methods while using Activity theory as an analytical framework [40]. Quantitative data coming from the questionnaires were analyzed using descriptive methods such as frequency analysis using Statistical Package for Social Sciences (SPSS). The mLA network was analyzed using NodeXL version 1.0.1.251.

\section{C) Evaluation of $m L A$ as learning tool}

A pre and post-test analysis was conducted to test the knowledge gain among the learners. Pre-test data were collected daily based on the learner-answers posted in the mLA while post-test data were collected from Twitter based assesments. Data were analyzed using a paired t-test using SPSS.

\section{FINDINGS}

\section{A) User requirements analysis}

User requirements and design specifications for mLA were identified during the problem analysis phase using participatory methods. Fig. 2 presents the most important considerations.

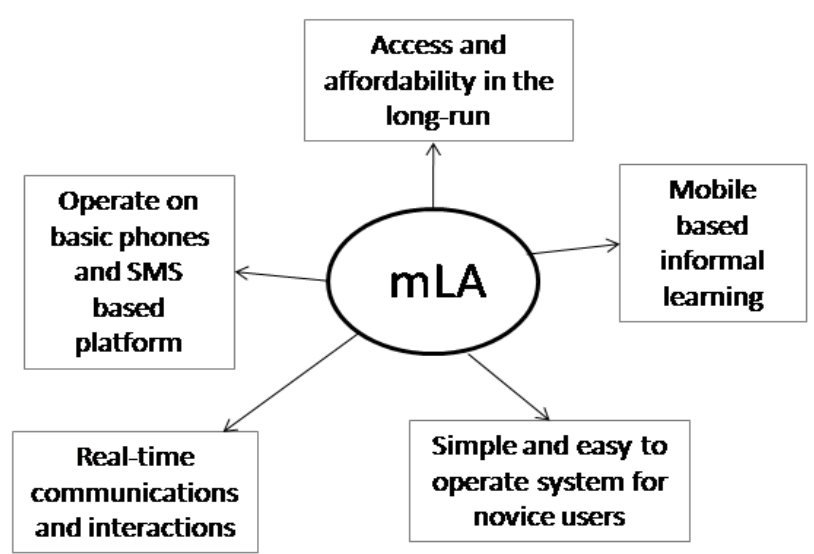

Fig. 2. User requirements

Facilitating real-time communications and interactions among user community was a main requirement. This enabled sharing information, promoting collaborative learning, and providing feedback during learning. Secondly, the study community required the system to support basic phones and SMS facility, as majority (74\%) had access to basic phones [2]. Thirdly, user group wanted to use mLA in facilitating mobile-based guided-informal learning. Access and affordability in the long term was another concern.

\section{B) Designing user network}

First step of the implementation process was to set up a network to link learners with the learning community. The network developed using the web application of the Twitter micro-blogging site (https://twitter.com). Twitter service is available as a web based application, ios, android, mobile web application and SMS based application making it easier to use in any type of a mobile phone. Considering the heterogeneity of mobile phones available among the users,
SMS based methods found to be more appropriate. Hence, mobile SMS based Twitter was used in designing the SMS gateway for the mLA (Fig. 3). Initially, learners connected to the two instructors, e.g. agricultural instructor (I1) and one researcher (I2). Later, the learners allowed to communicate with the other learners.

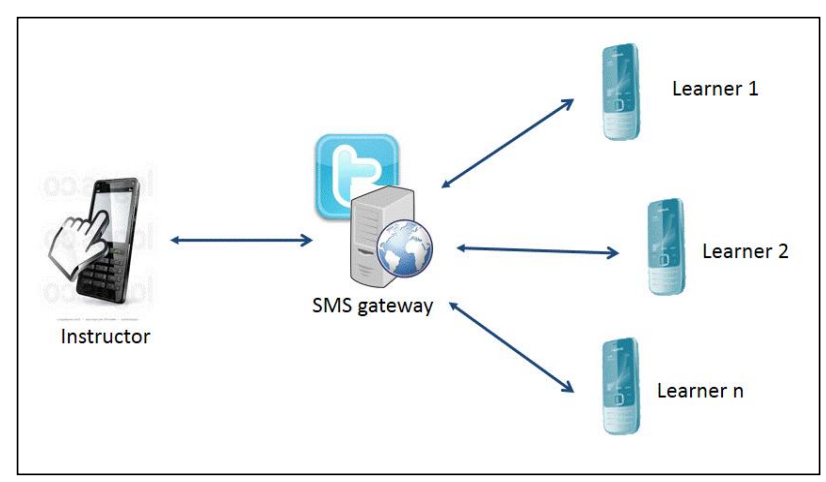

Fig. 3. SMS gateway of the mLA

User network of the mLA is visualized in Fig. 4 using NodeXL application. Since Twitter relationships are asymmetric in nature, user network analyzed using a directed graph, which allowed identifying key individuals in the community.

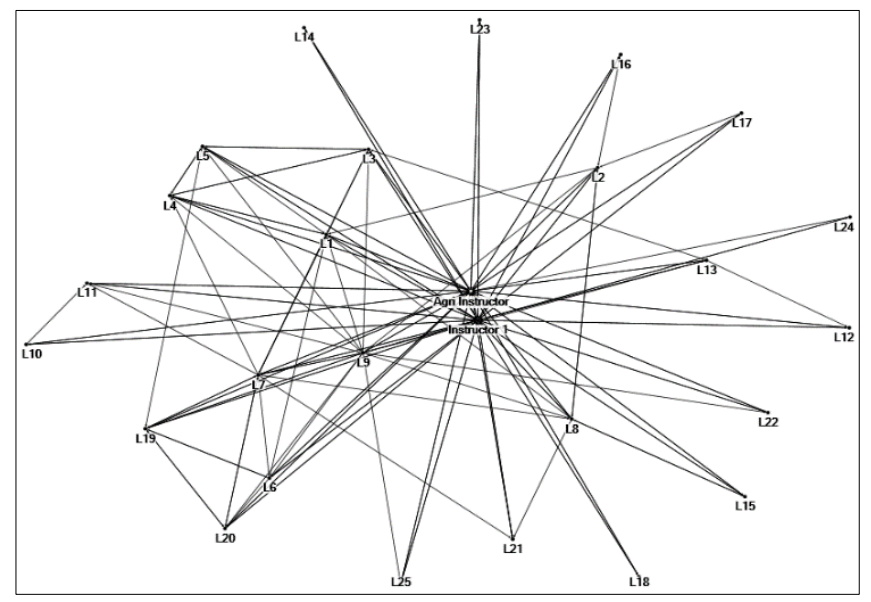

Fig. 4. User network for the mLA

The instructors played a central role in the mLA network. They posted questions in the mLA, shared learning resources, interacted with learners, and provided feedback. The two instructors formed the basis for the mLA model, and all the learners linked to instructors. Graph matrices of the user network is presented in Table 1. The network consisted of 25 farmers and two instructors, while there were 158 connections in the network. More than $79 \%$ of the connections are reciprocated. The average geodesic distance is 1.66 , indicating that each learner in the network can reach any other learner by walking through maximum two steps.

Graph density refers to the ratio between existing connections in a network and the maximum number of connections that are possible within the network. The density of the network is about 0.22 , indicating that only $22 \%$ of connections formed in the network. One possible reason for the lower density was due to technical limitations. Most of 
the learners (88\%) accessed mLA using a basic mobile phone, with SMS facility. This limited the number of connections that they can effectively maintain in a SMS based system. For instance, in a web-based system or in a smart-phone based system, all users can be linked with any other learner they wanted. However in the mLA, most learners had to connect with maximum 2-5 other learners in order to keep the system simple. The web based mLA was mainly used by the instructors.

Table 1. Graph matrices

\begin{tabular}{|l|r|}
\hline Graph Type & Directed \\
\hline Vertices & 27 \\
\hline Unique Edges & 158 \\
\hline Edges With Duplicates & 0 \\
\hline Total Edges & 158 \\
\hline Self-Loops & 0 \\
\hline Reciprocated Vertex Pair Ratio & 1 \\
\hline Reciprocated Edge Ratio & 27 \\
\hline Connected Components & 0.663157895 \\
\hline $\begin{array}{l}\text { Maximum Vertices in a Connected } \\
\text { Component }\end{array}$ & 0.797468354 \\
\hline $\begin{array}{l}\text { Maximum Edges in a Connected } \\
\text { Component }\end{array}$ & 2 \\
\hline Maximum Geodesic Distance (Diameter) & 1.665295 \\
\hline Average Geodesic Distance & 0.225071225 \\
\hline Graph Density & \\
\hline
\end{tabular}

C) Designing pedagogical tools

Designing pedagogical tools were addressed in two phases: i). Study features of Twitter and how to use them in designing mLA platform, ii) designing pedagogical tools.

1) Twitter functionalities: Features, functionalities and related applications of Twitter were studied to see how to use these features in designing the mLA platform. For instance, features in Twitter, such as tweet, re-tweet, and direct message, were explored to see their usability in an mLearning environment (Fig. 5).

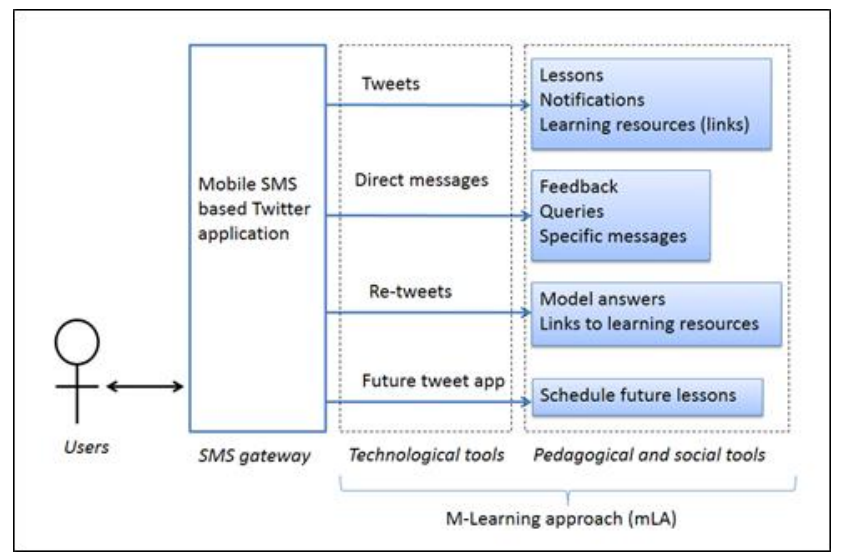

Fig. 5. Twitter functionalities used in designing mLA

Tweets or Twitter message option was used to post lessons, notices, and to share web links for learning resources.
Twitter Direct message option was used to give feedback for individual learners, answer queries made by learners and interactions with learners. Re-tweet option was used to share interesting answers and learning resources posted by the learners. Future tweet app was used to schedule lessons.

2) Developing learning contents: Pedagogical tools such as lesson objectives, learning contents, feedback and assessments were developed to match with features and functionalities of Twitter. The lesson objectives were designed to impart cognitive skills at the first two levels of Blooms' Taxonomy of cognitive domain, i.e. knowledge and comprehension (Box 1). Learning community was interested in knowing and remembering simple facts and specific pieces of information related to agricultural practices. Remembering information was essential for them to take part in a national quiz competition held among young farmer communities.

Box 1. Lesson objectives and learning contents

Lesson objective: After following lesson 1, the learners should be able to explain the 'benefits and specifications of using paddy husk ash as a soil nutrient in rice cultivation' with $100 \%$ accuracy

\section{Question 1a)}

What are the advantages of using paddy husk ash in paddy cultivation?

\section{Model answer 1a)}

Paddy husk ash adds Potassium to the soil, preventing incidences of lodging and possible incidences of iron toxicity

Question 1b)

How many kilograms of paddy husk ash would be sufficient for 1 acre paddy land? a. 250kg; b. 2000kg; c. 1000kg; d. 500kg

\section{Model Answer $1 b$ )}

About $250 \mathrm{~kg}$ of paddy husk ash necessary for 1 acre paddy land

Learning contents were developed in collaboration with the agriculture instructor. Learning contents that were used in the traditional face-to-face discussion classes were considered as the benchmark when designing the learning objectives.

A Twitter post allows only 140 characters per message thus lessons were planned to be less than 140 characters per message.

Each lesson were planned as having two components; a question and a model answer. There was a delay of 4-6 hours between the question and model answer so that learners have time to find the correct answer for the question. Learners posted their answers in the mLA in response. Instructors provided feedback, and clarified queries using Twitter direct message option. Box 2 shows lesson objectives and contents designed.

Altogether 144 short lessons were prepared and validated with the Agricultural Instructor initially. Both open ended questions and multiple choice questions were included when constructing lessons. More open-ended questions were (76\%) planned so that learners can post their own answers. 
It also helped in initiating discussions and facilitating learner collaborations at a different level. Box 2 shows a question posted by the instructor in the mLA is being answered by a learner. Multiple choice questions were used when it is important to give clues helping learners guess the correct answer. All the learning contents were developed in local language, and typed using English fonts as they would use them in speech. This method was familiar to the user community and it was the customary procedure to send and receive SMSs. Almost all the users have learnt English as the secondary language for eight years or more, thus they were familiar with this method. Terms such as "question" and "answer" were used when necessary.

Box 2. A question posted by the instructor is answered by a Learners

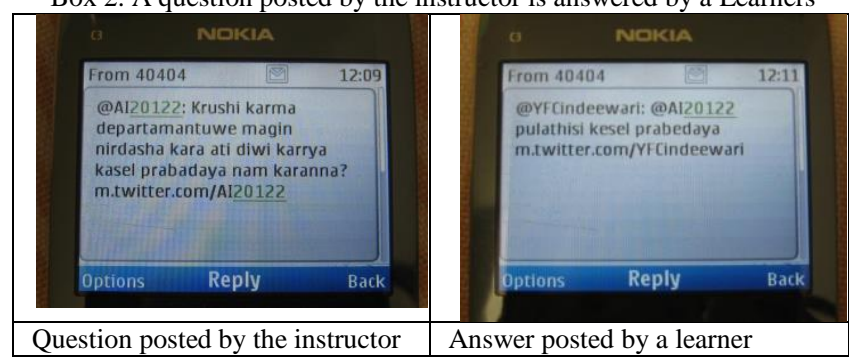

Initially the lessons were posted by the instructor2 (https://twitter.com/Agriq), while later stages this responsibility was gradually transferred to the agricultural instructor (https://twitter.com/AI2012). Lessons were scheduled using Future Tweet app (http://futuretweets.com) so that lessons are sent to the learners at a regular time of the day. Both instructors interacted with the learners to give feedback, and clarifying queries raised by the learners. Furthermore, the agriculture instructor posted messages in the mLA in communicating important messages to the young farmer community, scheduling meetings with the group, and informing them on relevant training programmes arranged locally.

3) Interactions in the $m L A$ : The instructor initiated the learning process by posting a simple question at the mLA (Fig. 6). The learners are supposed to find answer for the question and post the answer in the mLA.
When a learner finds it difficult to answer on their own they can seek help with a friend, interact with the instructors or refer learning resources. Learning resources included agricultural publications, and electronic resources such as websites of the agricultural institutions.

4) Feedback and rewarding: Interactions with instructors have also lead to have a better understanding and additional details. The instructor offered learner specific feedback and guided-learners in the learning process (Fig. 7).

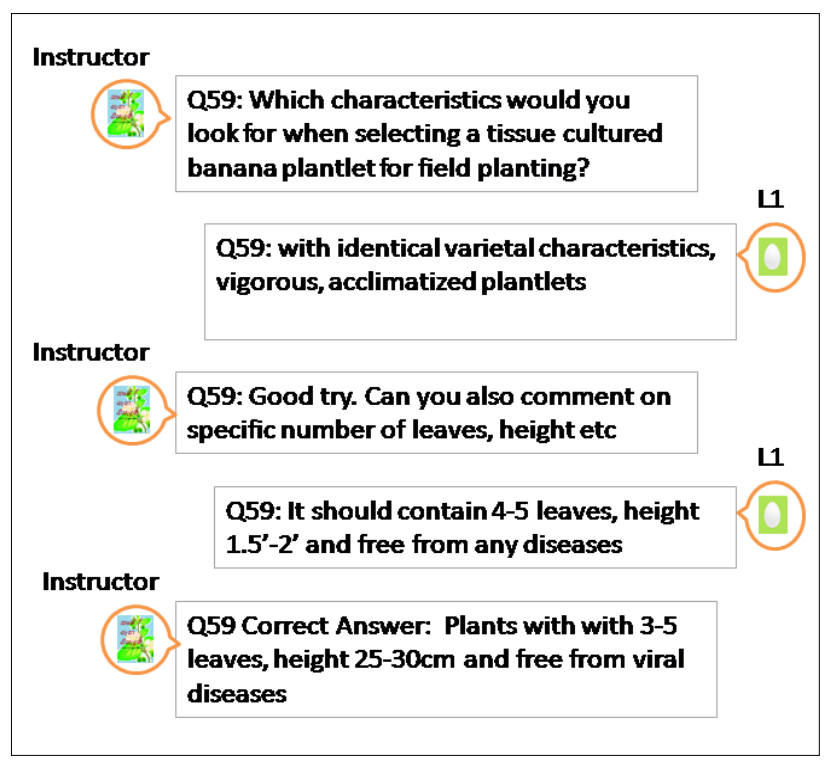

Fig. 7. A learner interacting with instructor in the mLA

Feedback given to the learners saying whether the answer is right or not. The instructor also recommends suitable learning resources, provided clues on how to find the answer. At the end of the lesson, instructor posted a model answer in the mLA. This process enabled the individual learner to construct his own knowledge about the subject matter. The other learners and the instructor assist the learner during the learning process. It was observed that most of the learners were able to find the correct answer through the interactions and were able to post it in the mLA. The model answers and

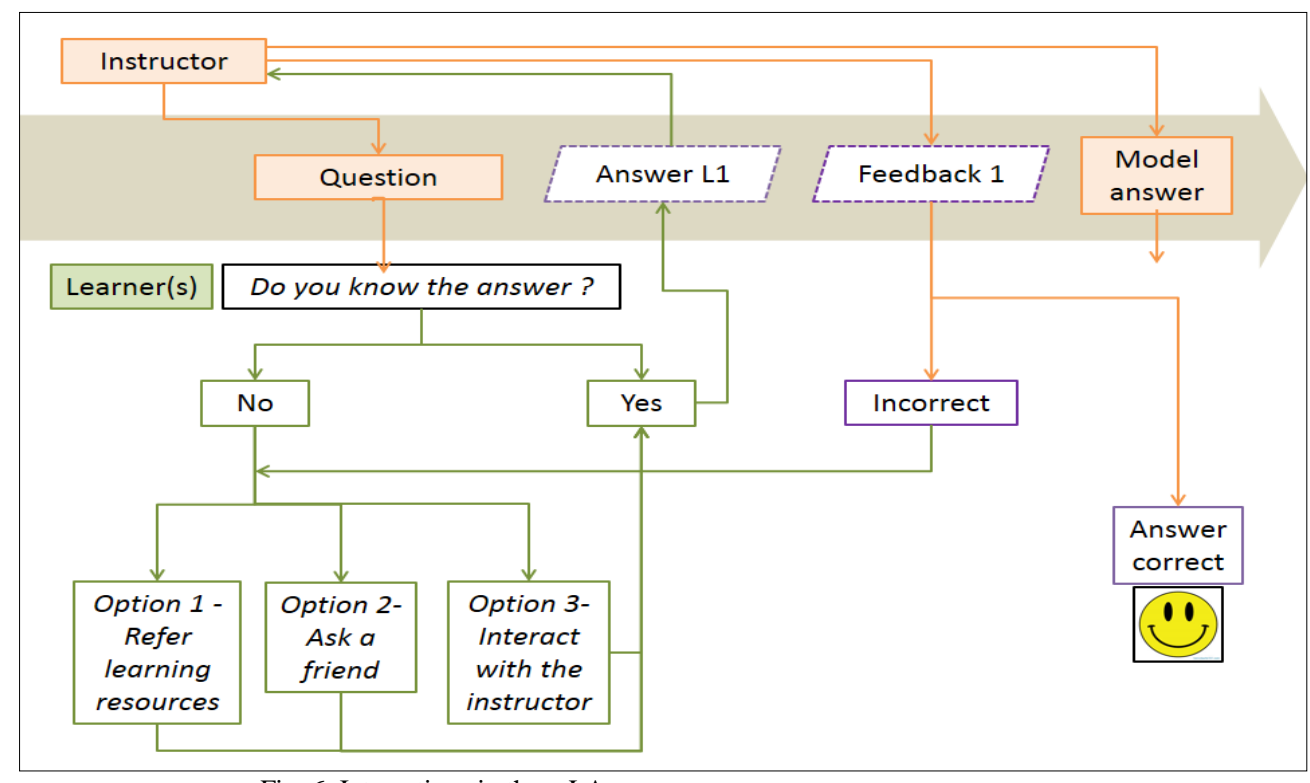

Fig. 6. Interactions in the mLA 
the feedback offered by the instructor helped in reinforcing the learning process.

Four types of feedback were given to the learners. First, individual feedback was given when the learners attempt to answer the lesson-question as given in Fig. 7 above. Secondly, feedback was given to the whole group at the end of the lesson by sharing which learners have sent the correct answers for the mLA question. Thirdly, best answers of the day shared with all the users. Finally, total marks obtained by each learner when they post answers for mLA questions were shared with the whole group. Efforts were made to stick to the best practices in offering formative feedback such as being specific and clear with feedback messages [16].

A reward in a learning environment can be defined as something given to learners in recognition of their achievements or performances. Establishing formal or informal rewards have improved student's participation in mobile learning projects [41], [42] and enhanced positive feelings towards the learning process [43]. A rewarding system was introduced to motivate learners in participating in the mLA. Learners were rewarded for posting answers and for interacting in the mLA.

5) Assessments: Assessments were conducted to gather information on learner performances. Learner performances were evaluated in relation to learning objectives using short tests. These tests were designed to give feedback for learners on their performances. Box 3 shows a short test conducted to evaluate learner performances. Three short tests were conducted monthly; each test had 4-5 questions. A summative assessments were also conducted at the end of the mLA 2 using a paper based test.

\section{D) Effectiveness of mLA as a learning tool}

The mLA had shared about 229 lessons during its implementation (Table 2). Total number of posts in the mLA was around 2890 . There were 28 learners in the mLA and together they have posted more than 2000 short messages in the mLA mainly using basic phones and SMS based Twitter. During the mLA2 implementation, the role of instructor was mainly fulfilled by the researcher while mLA3 implementation, the agricultural instructor contributed as the instructor.

Table 2. mLA logged data analysis

\begin{tabular}{|l|l|}
\hline Criteria & Number of posts \\
\hline Number of learners & 28 \\
\hline Number of instructors & 2 \\
\hline Total number of lessons & 229 \\
\hline $\begin{array}{l}\text { Total number of posts in the mLA } \\
\text { (I1 + I2) }\end{array}$ & 870 \\
\hline $\begin{array}{l}\text { Total number of communications } \\
\text { by learners (subjects) }\end{array}$ & 2020 \\
\hline
\end{tabular}

The effectiveness of mLA as a learning tool was determined by comparing the knowledge level of the learners before and after test analysis (Table 3).

A mean comparison was performed using one sample ttest using the Statistical Package for Social Sciences (SPSS). According to the results there was a significant difference between the average mean score of learners before mLA and after mLA implementation. The results show that the mLA is highly effective as a learning tool.

\begin{tabular}{|c|c|}
\hline $\begin{array}{l}\text { Agriculture quiz @Agriaz · } 23 \text { Nov } 2012 \\
\text { Test 2: } \\
\text { Methan sita obata labena prashna sadaha pilithuru, prashna ankaya } \\
\text { samaga } 40404 \text { ta sms karanna. }\end{array}$ & $\begin{array}{l}\text { Translation } \\
\text { TEST 2: Beginning Test 2; Please SMS your answers to } \\
40404 \text { with the question number. }\end{array}$ \\
\hline $\begin{array}{l}\text { Agriculture quiz } @ \text { Agriqu } \cdot 23 \text { Nov } 2012 \\
\text { Test2-q1: Ekabaddha paliboda palanayedi, anugamanaya kala haki kriya } \\
\text { marga monavada? }\end{array}$ & $\begin{array}{l}\text { T2-Q1: Explain } 3 \text { important IPM (Integrated Pest Manage- } \\
\text { ment) practices. }\end{array}$ \\
\hline $\begin{array}{l}\text { Agriculture quiz @ Agriqz } \cdot 23 \text { Nov } 2012 \\
\text { Test2-q2: Kohoba gase, palibodanasaka gunaya vadima shaka kotasa } \\
\text { kumakda? }\end{array}$ & $\begin{array}{l}\mathrm{T} 2-\mathrm{Q} 2 \text { : Which plant part of the neem having strongest in- } \\
\text { sect-repellent qualities? }\end{array}$ \\
\hline $\begin{array}{l}\text { Agriculture quiz@Agriqz } \cdot 23 \text { Nov } 2012 \\
\text { Test2-q3: Thilini saha Thilina prabeda ayath vana boga varga } 2 \\
\text { monavada? }\end{array}$ & $\begin{array}{l}\text { T2-Q3: Which of the two crop groups have 'variety Thil- } \\
\text { ina' and 'variety Thilini'? }\end{array}$ \\
\hline $\begin{array}{l}\text { Agriculture quiz @Agriqz · } 23 \text { Nov } 2012 \\
\text { Test2-q4: Oba danna malu miris prabheda } 2 \mathrm{k} \text { nam karanna. }\end{array}$ & $\begin{array}{l}\text { T2-Q4: Give an example for a capsicum variety recom- } \\
\text { mended by the DOA? }\end{array}$ \\
\hline $\begin{array}{l}\text { ․ㅐㄱ. Agriculture quiz @Agniqz - } 23 \text { Nov } 2012 \\
\text { Test2-q5: Ape rate purna kalina govin prathishathaya kopamanada? }\end{array}$ & $\begin{array}{l}\text { T2-Q5: State the percentage of fulltime farmers in Sri } \\
\text { Lanka. }\end{array}$ \\
\hline $\begin{array}{l}\text { 7. Agriculture quiz @Agriqz } \cdot 23 \text { Nov } 2012 \\
\text { End of Test 2: Sahabagi vima venuven sthuthi. Suba sathi anthayak. }\end{array}$ & End of Test 2; thanks for your participation \\
\hline
\end{tabular}


The mean score for the learners before implementing mLA was $39 \%$ while this has significantly improved up to $70 \%$ after participation in the mLA.

Table 3. Results of the mean comparison

\begin{tabular}{|l|l|l|l|l|l|l|}
\hline & t value & Df & $\begin{array}{l}\text { Sig. } \\
(2- \\
\text { tailed })\end{array}$ & $\begin{array}{l}\text { Mean } \\
\text { difference }\end{array}$ & \multicolumn{2}{|l|}{$\begin{array}{l}\text { 95\% Confidence } \\
\text { Interval of the } \\
\text { Difference }\end{array}$} \\
\hline & & & & & Lower & Upper \\
\hline $\begin{array}{l}\text { Before } \\
\text { mLA }\end{array}$ & 5.239 & 12 & .000 & 39.03134 & 22.7987 & 55.2639 \\
\hline After mLA & 7.878 & 12 & .000 & 70.32967 & 50.8783 & 89.7811 \\
\hline
\end{tabular}

During the summative evaluations, learners were asked to identify three new things they have learnt due to $\mathrm{mLA}$ exercises. Interestingly highest number of learners $(80 \%)$ suggested Twitter social media and its usage as a learning tool and a networking tool. Almost all were new to Twitter micro-blogging service and it could be the reason as to why the learners identified it as a new learning experience. Agriculture best practices and latest technologies in agriculture were noted by $66 \%$ of the respondents. About $26 \%$ of the respondents mentioned that mLA helped them to improve IQ and general knowledge, while a similar percentage related to their mLA experience as an exposure to mobile technology enhanced learning solutions (Fig. 8).

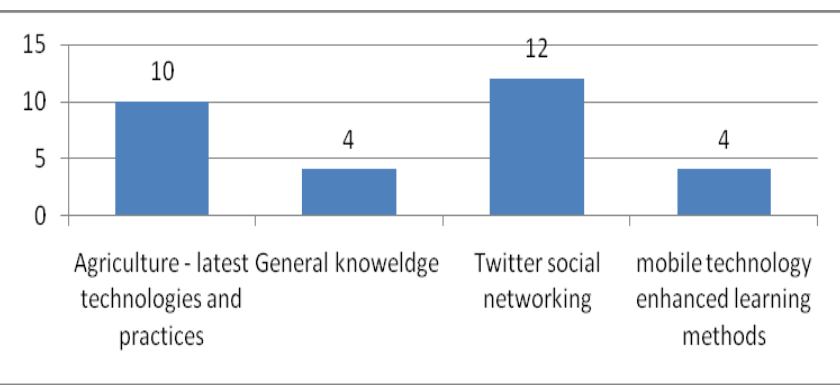

Fig. 8. Learning outcomes

The learner experiences of using the mLA3 was measured using five statements on a 5 point Likert scale, in which $1=$ highly un-favourable and 5=highly favourable. The Table 4 presents average ratings given by the learners on various aspects of mLA experiences. It is seen that the majority of the learners were satisfied with the performance and use of the mLA3.

Table 4. Learners' reactions to mLA

\begin{tabular}{|l|c|}
\hline \multicolumn{1}{|c|}{ Statements } & $\begin{array}{c}\text { Rating } \\
(\mathbf{n = 8})\end{array}$ \\
\hline mLA was helpful in improving knowledge & 4.875 \\
\hline $\begin{array}{l}\text { Mobile learning can be successfully } \\
\text { implemented among young farmer communities }\end{array}$ & 4.875 \\
\hline I am highly satisfied about the mLA experience & 4.75 \\
\hline $\begin{array}{l}\text { The agriculture instructor played a mediating } \\
\text { role that was very important for the success of mLA }\end{array}$ & 5 \\
\hline
\end{tabular}

It is important that the learners and instructors 4.875 having a good mutual understanding for the successful implementation of mLA

\section{E) Problems and limitations in the $m L A$}

About $21 \%$ of learners commented that they had problems in reading lessons, which typed using English fonts. This was particularly related to certain technical terms that were unfamiliar to them. Since these learners were not previously exposed to these technical terms, it was difficult for them to read and understand the message when it is presented in English fonts and not in the local language. This can be considered as a major limitation in mLA as it does not allow learners to communicate in local language which is more familiar for them.

Even though many users interacted with their peers and instructor to find answers for mLA questions, about one third $(35 \%)$ of learners said they gave up on mLA questions when they did not know the answer. These users have felt that they should not be disturbing others by sending a Twitter direct messages, SMSs or calls. They commented that they could not participate in mLA as much as they wanted mainly because they did not know the correct answers for mLA questions. This problem has arisen mainly because mLA did not have an inbuilt facility such as a forum to discuss answers with peers. If there was a common discussion forum in mLA, most users could make use of it to discuss answers. Some users (14\%) mentioned that they could not adequately answer questions posted in mLA because they have not studied agriculture as a subject at school. It was only one third $(36 \%)$ of the respondents who had studied agriculture as a subject during school years. This group of learners, who were already exposed to a formal system of agriculture education, was seen as more knowledgeable than the others.

The respondents were asked to rank the usefulness of the learning contents given in the mLA using a three point scale (very useful, useful, and not useful). Almost all the respondents agreed that the learning contents presented in the mLA was either very useful $(78.6 \%)$ or useful $(21 \%)$. However, few suggestions came from the users on how to improve the mLA in order to make it more useful as a learning tool. For instance, a few learners suggested that it would be beneficial if the mLA included more lessons related to field problems in agriculture, and allow the learners to post question forward agriculture field problems they have experienced directly to the mLA so that the agriculture instructor can post answers to those questions.

Technical problems related to receiving tweets in the mobile phone were another drawback. Some users could not receive tweets in their mobile device and the situation could not be enhanced even after consultation with the service providers. This de-motivated them in taking part in mLA.

The mLA mostly supported learners to acquire cognitive skills up to the first two levels of Blooms taxonomy, namely knowledge and comprehension. The SMS based platform of the mLA were more appropriate in imparting basic skills in the cognitive domain, however opportunities in moving towards higher order learning skills was not satisfactory.

Effective number of learners that can be linked in the Twitter based mLA was limited to 5-7, due to its SMS based platform. linking with many other learners meant that a user would get a number of SMSs everyday making it difficult for them to manage with their daily commitments. The 
instructors mainly operated their mLA accounts using a web based platform, however most learners did not have this facility.

\section{DISCUSSION}

Question and answer format was an appropriate solution to overcome character limitation in Twitter. Firstly, and most importantly it allowed breaking a single lesson into two meaningful components to overcome 140 character limitations per message. Secondly, it actively engaged learners in the learning process as they were encouraged to find an answer to a given question and post in the mLA. Thirdly, it allowed meaningful interactions with instructors and other learners, enhancing opportunities for collaborative learning. Finally, the model answer was not only helpful for learners who did not know the answer to learn it, but also whose predicted the correct answer had their learning experience reinforced.

When asked the respondents to compare m-learning experience with the traditional non-formal learning system. Learners acknowledge that they can 'share more information during non-formal classes, and get the problems clarified by the instructor during non-formal classes' all of which lead to achieving higher order learning skills. On the other hand, the mLA helped learners in interacting with the other learners every day from anywhere and at any time. Learners saw this as an important feature as they understand the difficulties in arranging non-formal classes frequently. Given the fact that farmers pre-occupied with other priorities, it was difficult for all the interested farmers to take part in a non-formal class. The mLA provided a solution for these farmers to learn new practices of agriculture.

Heterogeneity of phone types available among users was a major consideration when designing the mLA. The majority of the users had basic phones, while a few had Smartphones and Java enabled phones. Thus, users wanted a system that can also use with a basic phone. Text messages were the most frequently used communication method among the user community thus, they felt comfortable with using an SMS based method to communicate and interact among the community.

The study community wished to improve their knowledge on two aspects; agricultural practices and general knowledge. They needed the system to deliver short lessons, which they can work on during their leisure time. The users preferred to have learning contents broken into shorter lessons, one at a time, so that it is easy to comprehend. Furthermore, they wanted to collaborate with the instructors and other learners using the system.

Use of an established social networking service had several benefits. Availability of the technology for the users for long-term use with a less or no maintenance cost was an important concern. Twitter is freely available on a web-based platform. On a mobile SMS platform, the service providers charge a nominal fee for each SMS sent to the network while SMSs are delivered free. The users agreed that the nominal fee for sending SMS is cost effective and affordable.

Three of the major mobile service providers hosted Twitter under its universal short code 40404. This makes the application more accessible to the user community as all the users had access to one or more of the above mobile service providers.
On the negative side, one of the main challenges in SMS based learning methods is the character limitation per message. During this study, the maximum number of characters allowed was 140 . Use of the local language to compose messages had made it even lesser because the messaged need to be typing in English fonts. In this situation, it was a challenge to compose lessons as it was necessary to select the most appropriate set of words and has to be within 140 characters per message. The lessons had to be 'meaningful yet concise with simple language' [21]. Sometimes it was necessary to break the lesson into three or more segments; however, in a typical lesson there were only two segments namely question and model answer. When it is necessary to provide more information, additional SMSs sent just after posting the question or model answer.

\section{CONCLUSIONS}

Learners were generally satisfied with the mLA based guided-informal learning experience and had favourable attitudes towards the mobile learning approach. The mLA was an effective learning tool, which assisted learners in constructing knowledge, providing feedback, reinforcing learning, and facilitating collaborative learning.

Lessons formulated as questions \& answers format seen as an appropriate solution to overcome character limitation in Twitter platform. It also allowed splitting the lesson into two meaningful segments, making lessons more challenging for the users thus, improving user engagement. Considering the small screen size of mobile devices, Q\&A format also avoided publishing bulky material.

There were a few drawbacks in the mLA with regard to technical difficulties in receiving tweets in the mobile phone, difficulty in moving for higher order learning skills, and limited opportunities for collaborations due to SMS based platform. The mobile SMS based platform in the mLA did not provide enough room to connect learners with each other. Nearly one fifth of connections could be established in mLA as the majority of users accessed mLA using basic phones. However, all the learners were linked with instructors, thus effective collaborations were mostly seen between instructors and learners in the mLA. Due to this reason, many learners sought to contact others outside the mLA system, using communication methods such as SMSs, personal calls, and face-to-face discussions.

Learners will need more technical support and assistance together with better interface to promote collaborative learning opportunities in the future. In future research, it is necessary to extend the mLA model as a mobile application in a Smartphone environment.

\section{ACKNOWLEDGEMENT}

The authors wish to acknowledge financial support given by the Higher Education in the 21st Century (HETC) project funded by the World Bank, and all the members and the Agriculture Instructors of the Young Farmer ClubAnkumbura for their active participation in the study.

\section{REFERENCES}

[1] T. M. Duffy and D. H. Jonassen, "Constructivism: New implications for instructional technology," in Constructivism and the technology of instruction: A conversation, 1992, pp. 103-128.

[2] U. Dissanayeke, K. P. Hewagamage, R. Ramberg, and G. N. Wikramanayake, "Study to initiate Mobile Learning among a group of 
Young Farmers from Kandy District: An Activity Theory based approach," Trop. Agric. Res., vol. 26, no. 1, pp. 26-38., 2014. [3] U. Dissanayeke, K. P. Hewagamage, R. Ramberg, and G. N. Wikramanayake, "Creating m-Learning Opportunities to Facilitate Collaborative Learning : A Mobile SMS based Twitter Implementation," in international Conference on Advances in ICT for Emerging Regions (ICTer), 2014, vol. 14, pp. 49-54.

[4] E. Murphy, "Constructivism : From Philosophy to Practice," 1997. [5] H. So and C. J. Bonk, "Examining the Roles of Blended Learning Approaches in Computer- Supported Collaborative Learning ( CSCL ) Environments : A Delphi Study Blended Learning : From Delivery Technology to Learning Technology," vol. 13, pp. 189-200, 2010. [6] G. Zurita and M. Nussbaum, "A constructivist mobile learning environment supported by a wireless handheld network," J. Comput. Assist. Learn., vol. 20, pp. 235-243, 2004.

[7] J. J. S. Huang, S. J. H. Yang, Y. Huang, and I. Y. T. Hsiao, "Social Learning Networks : Build Mobile Learning Networks Based on Collaborative Services," Educ. Technol. Soc., vol. 13, no. 3, pp. 78-92, 2010.

[8] D. DeWitt and S. Siraj, "Design and development of a collaborative mlearning module for secondary school science in Malaysia: addressing learners' needs of the use and perceptions of technology," Procedia - Soc. Behav. Sci., vol. 2, no. 2, pp. 471-475, Jan. 2010.

[9] A. Kukulska-Hulme, M. Sharples, M. Milrad, I. Arnedillo-S'anchez, and G. Vavoula, "Innovation in Mobile Learning: A European

Perspective,” Int. J. Mob. Blended Learn., vol. 1, no. 1, pp. 13-35, 2009.

[10] L. Naismith, P. Lonsdale, G. Vavoula, and M. Sharples, "Literature Review in Mobile Technologies and Learning," Educ. Technol., vol. 11, pp. 1-25, 2004.

[11] Y. Laouris and N. Eteokleous, "We need an educationally relevant definition of mobile learning," in mLearn 2005 :4th World conference on mLearning, 2005, no. June, pp. 290-294.

[12] H. Crompton, "A historical overview of m-learning: Toward learnercentered education.," in Handbook of mobile learning, Z. L. Muilenburg and L. Y. Berge, Eds. Florence, KY: Routledge, 2013, pp. 3-14. [13] D. W. Mocker and G. E. Spear, "Lifelong Learning: Formal, nonformal, informal, and self-directed." National Center Publications,

National Center for Research in Vocational Education, 1960 Kenny Road, Columbus, OH 43210 (IN241, \$3.75)., 1982.

[14] D. R. Sadler, "Formative assessment and the design of instructional systems," Instr. Sci., vol. 18, no. 2, pp. 119-144, 1989.

[15] C. Garrison and M. Ehringhaus, "Formative and Summative Assessment in the Classroom," 2007. [Online]. Available: http://ccti.colfinder.org/sites/default/files/formative_and_summative_asses sment_in_the_classroom.pdf. [Accessed: 11-Nov-2014].

[16] V. J. Shute, "Focus on Formative Feedback," New Jersey., 2007.

[17] J. M. Keller, "Strategies for stimulating the motivation to learn,"

Performance+ Instr., vol. 26, no. 8, pp. 1-7, 1987.

[18] K. Petrova, "An implementation of an mLearning scenario using short text messaging : an analysis and evaluation," Int. J. Mob. Learn. Organ., vol. 4, no. 1, pp. 83-97, 2010.

[19] N. Cavus and H. Uzunboylu, "Improving critical thinking skills in mobile learning," Procedia - Soc. Behav. Sci., vol. 1, no. 1, pp. 434-438, Jan. 2009.

[20] I. Ismail, R. Mohammed Idrus, and S. S. Mohd Johari, “Acceptance on Mobile Learning via SMS: A Rasch Model Analysis," International Journal of Interactive Mobile Technologies (iJIM), vol. 4. 2010.

[21] T. Lim, M. Fadzil, and N. Mansor, "Mobile Learning via SMS at Open University Malaysia: Equitable, Effective, and Sustainable," Int. Reveiw Res. Open Distance Learn., vol. 12, no. 2, pp. 122-137, 2011. [22] T. Elias, "Universal Instructional Design Principles for Mobile Learning,” Int. Rev. Res. Open Distance Learn., vol. 12, no. 2, pp. 143-56, 2011.

[23] N. Capuano, M. Gaeta, S. Miranda, and L. Pappacena, "A system for adaptive platform-independent mobile learning," in mLEARN 2004, 2004, pp. 53-56.

[24] F. Wang and M. J. Hannafin, "Design Based Research and Technology-Enhanced Learning Environments,” Educ. Technol. Res. Dev., vol. 53, no. 4, pp. 5-23, 2005.

[25] S. Barab and K. Squire, "Design-Based Research : Putting a Stake in the Ground,” J. Learn. Sci., vol. 13, no. 1, pp. 1-14, 2009.

[26] C. Alvarez, R. Alarcon, and M. Nussbaum, "Implementing

collaborative learning activities in the classroom supported by one-to-one mobile computing: A design-based process," J. Syst. Softw., vol. 84, no.

11, pp. 1961-1976, Nov. 2011.

[27] J. Nouri, T. Cerratto-pargman, J. Eliasson, and R. Ramberg,

"Exploring the challenges of supporting collaborative mobile learning," 2009.

[28] J. Eliasson, D. Spikol, T. C. Pargman, and R. Ramberg, "Get the bees away from the hive : Balancing visual focus on devices in mobile learning," no. 2008, pp. 77-84, 2010.

[29] S. Hsi, "I-Guides in Progress : Two Prototype Applications for Museum Educators and Visitors Using Wireless Technologies to Support Informal Science Learning," 2000, pp. 1-5.

[30] C. M. Hoadley, "Methodological Alignment in Design-Based Research,” Educ. Psychol., vol. 39, no. 4, pp. 203-212, Dec. 2004. [31] E. Kassens-Noor, "Twitter as a teaching practice to enhance active and informal learning in higher education: The case of sustainable tweets," Act. Learn. High. Educ., vol. 13, no. 1, pp. 9-21, 2012.

[32] M. Ebner, C. Lienhardt, M. Rohs, and I. Meyer, "Microblogs in Higher Education - A chance to facilitate informal and process-oriented learning?," Comput. Educ., vol. 55, no. 1, pp. 92-100, Aug. 2010. [33] J. Dunlap and P. Lowenthal, "Tweeting the night away: Using Twitter to enhance social presence,” J. Inf. Syst. Educ., vol. 20, pp. 129-136, 2009.

[34] L. Chen and T.-L. Chen, "Use of Twitter for formative evaluation: Reflections on trainer and trainees' experiences," Br. J. Educ. Technol., vol. 43, no. 2, pp. E49-E52, Mar. 2012.

[35] W. Reinhardt, E. Martin, G. Beham, and C. Costa, "How People are using Twitter during Conferences," in 5th EduMedia Conference on Creativity and Innovation Competencies on the Web, 2009, no. March, pp. $145-156$.

[36] R. Junco, G. Heiberger, and E. Loken, "The effect of Twitter on college student engagement and grades," J. Comput. Assist. Learn., vol. 27, no. 2, pp. 119-132, Apr. 2011.

[37] K. Charitonos, C. Blake, E. Scanlon, and A. Jones, "Museum learning via social and mobile technologies: (How) can online interactions enhance the visitor experience?," Br. J. Educ. Technol., vol. 43, no. 5, pp. 802-819, Sep. 2012.

[38] G. Grosseck and C. Holotescu, "Can we use Twitter for Educational Activities," in 4th International Scientific Conference: eLearning and Software for Education, 2008

[39] T. Reeves, "Design research from a technology perspective," in Educational Design Research, J. van den Akker, K. Gravemeijer, S. McKenny, and N. Nieveen, Eds. New York: Routledge, 2006, pp. 52-66. [40] Y. Engeström, Learning by expanding: an activity theoritical approach to developmental research. Helsinki, Finland: Orienta-Konsultit Oy, 1987, p. 156.

[41] S. B. Rinaldo, S. Tapp, and D. a. Laverie, "Learning by Tweeting: Using Twitter as a Pedagogical Tool," J. Mark. Educ., vol. 33, no. 2, pp. 193-203, May 2011.

[42] N. Gedik, A. Hanci-Karademirci, E. Kursun, and K. Cagiltay, "Key instructional design issues in a cellular phone-based mobile learning project," Comput. Educ., vol. 58, no. 4, pp. 1149-1159, May 2012. [43] L. Visser and L. Systems, "Learner motivation and E-learning design: A multi-nationally validated process," J. Educ. Media, vol. 29, no. 3, pp. 229-39, 2004.

[44] S. R. Wagh and K. D. Bamane, "Twitter for University using Cloud," Comput. Eng. Intell. Syst., vol. 2, no. 6, pp. 26-33, 2011.

[45] Y. C. Hsu and Y. H. Ching, "Mobile microblogging: Using Twitter and mobile devices in an online course to promote learning in authentic contexts,” Int. Rev. Res. Open Distance Learn., vol. 13, pp. 211-227, 2012.

[46] T. B. Clarke and C. Leigh Nelson, "Classroom community, pedagogical effectiveness, and learning outcomes associated with Twitter use in undergraduate marketing courses," J. Adv. Mark. Educ., vol. 20, pp. $1-10,2012$.

[47] G. Vavoula and M. Sharples, "Meeting the Challenges in Evaluating Mobile Learning: A 3-level Evaluation Framework,” Int. J. Mob. Blended Learn., vol. 2, no. 1, pp. 54-75, 2009. 